\title{
EXPERIMENTAL PRACTICES TO DEVELOP FORMAL AND FORMATIVE PRINCIPLES FOR HANDICRAFTS
}

\author{
Eman Mohamed Wagdy EZZAT 1, 2,*
}

${ }^{1}$ Faculty of Specific Education, Aswan University, Egypt

${ }^{2}$ Taiba University, Kingdom of Saudi Arabia

\begin{abstract}
The research is concerned with reaching a contemporary design method by directly thinking about the material of the fabrics, the techniques of khayamia, and the embroidery with the stitches of the fabric added to the handicrafts represented in the use of scraps and remnants of fabrics from ready-to-wear factories in the implementation in a simple technical way, depending on plastic formulas in an abstract style, formulas that support the collage derived from Khayamia as a heritage method that is used in modern aesthetic formulations.

Keywords

Art, Education, Design, Community Culture.
\end{abstract}

\section{Introduction:}

The research is carried out to find a contemporary design method for thinking about the remnants of fabrics as a direct thinking, so that the element disassembles into geometric shapes and its background and begins to analyze and construct it with geometric formulations, "by breaking the barriers of the normal image in art, it no longer means breaking the aesthetic value itself, but rather a new vision of beauty, the phrase that Shakespeare put in the mouth of the Witches of Macbeth: " The beautiful is ugly and the ugly is beautiful" imposed its importance in the last years of the twentieth century (87-Lopes, Dominic McIver 2009) and left the place to a different vision in the postmodern period, as contemporary art seeks beauty in hybrid forms to reflect the transformations of technical and technological reality and the era, which is what forced this transformation in the aesthetic idea and in dealing with art with its expressive basis. The university is interested in linking college programs with the environment, culture and history of different civilizations as a trend in learning plastic practices, where the destiny of nations in the information age is linked to the creativity of their children, where the development of creativity in light of the education of the era and its culture, "it is the product of human activity; it is the creation of the individual who coexists with the natural environment and searches for means of adapting to it" (Mahmoud Al-Basyouni 1965-9).

Contemporary art has been greatly influenced by the digital technological development on the one hand and the amazing advancement in technical practices in various materials that reach the handicraft to a new form with formal and plastic principle for art formulations that enrich

*Corresponding author: drmanwajdy@gmail.com 
the design idea to produce marketable handicrafts from neglected materials in the environment, Throughout the ages, man used plastic techniques on cloth to express his aesthetic feelings for the purpose of decorating clothes and housing since the Pharaonic era, so he used gold wires to drape linen fabrics, and the method of synthesis and embroidery on fabrics attached to the walls of palaces, several samples of linen textiles similar to silk were found in Deir al-Bahari in Thebes, and "Tutankhamen's shirt, ribbons woven in the Khayamia style have been added in different places on the shirt as one of the forming methods used in different eras." (Hadeel Hassan Ibrahim, 1991-2), and in one of the graves of Saqqara from the Greek era a robe of gilded linen was found decorated with scenes from mythology Religious (Buthaina AbdelGawad Ahmed 1971-2)

(Saad Al-Khadem 1959-23) asserts, "Plastic techniques continued to be used in decorating clothes in successive eras, so Khayamia was known among the Copts in Egypt and continued in the Islamic era with the same methods in artistic crafts such as costume accessories and decorations for the headband with gold and silver threads and glass beads. "The popular heritage in the Nubia, Sinai and the oases is a method of synthesis with the handicrafts of cloth and its divisions, as "the folklore derived its various artistic and technical characteristics from its environment and its natural materials, so its features appeared clear on all the crafts it produces that are distinguished by originality in thinking linked to customs and traditions, and inherited cultural elements."(Abdul Hamid Yunus 1979-4) In addition, the plastic industries with embroidery and synthesis were found in the oases handicrafts. "So they used some stitches, whether on clothes or decorative accessories, with the use of colored sequins, shells, buttons and natural plants" (Ashraf Muhammad Abdel Qader 1989-9).

Artistic trends varied in the twentieth century, and its plastic principle became flexible and varied with modern formulas, so that every practitioner of art directs every style that suits him to plastic trends through experimental practices for plastic principle from the idea of implementation to the implementation of the idea, so the design thought varied through renewal from the ideal classic era to break the artistic rules in different schools of impressionism and brutality to Dadaism, abstraction, cubism and surrealism (Arts Gulf Newspaper, Thursday, Jumada-Al-Thani, 1441) so "the composition and assembly among the different materials to form a painting based on the most beautiful intellectual concept" (Zahraa Abdullah 2008-26), and throughout the ages, the concept of handicrafts has changed, so it has accepted various materials and techniques through which concepts, ideas, philosophies, and expressive and plastic values can be achieved by transforming them from traditional work to conceptual manual work with mental maturity and formative intellectual liberation in line with the 
prevailing technological thought". Some changes appeared in the methods of performance, especially in simulating some natural touches, so the practices were a stage and field for the idea of experimentation with materials and how to synthesize them - which led to the emergence of many new artistic concepts (Faten Al-Fadali 1992-3), "there is no doubt that the human touch in the design of the handicraft through the recycling of raw materials has a great impact on the transformation of its shape, if using modern technology." (Valentino Catricalà, Media Art), we find Stéphanie Kilgast transforming discarded garbage into vibrant ecosystems that burst with life as (1:3) "Nature taking over Art.
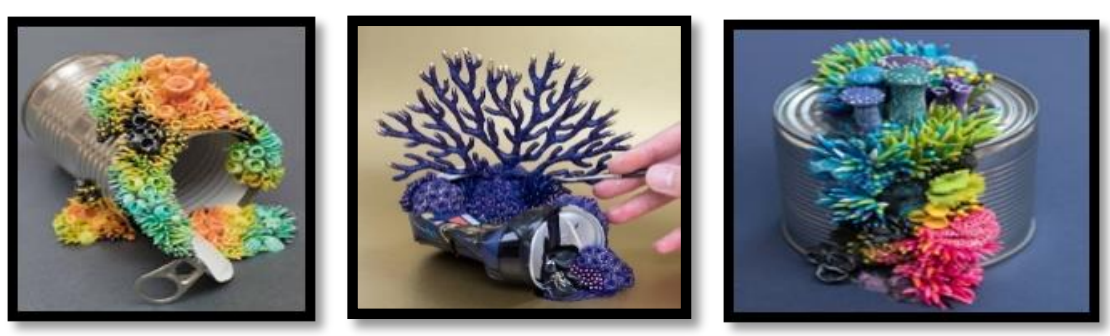

Figure (1: 3) Stéphanie Kilgast's figures transform discarded trash into vibrant ecosystems bursting with life

The arts, by their nature, are considered a social activity, in which they cooperate and exchange experiences among themselves, and this social interaction is to strengthen the bonds of love, tolerance and reduce intolerance, which has a great impact on creating a healthy and strong society and helps improve the country's economic, cultural and political situation. The arts inject additional funds into the state's treasury, by stimulating tourism, trade and reducing unemployment rates. In addition to attracting and enhancing the stability of capital and investors, the intellectual principles of shaping with environmental materials emphasize the importance of practicing experimentation in order for the individual to achieve his being and make him feel more satisfied with himself by strengthening some analytical and intellectual skills and abilities to help him improve his physical and psychological health, and the quality of his social life (Muhammad Hussein Judeh 1999-43)

UNESCO 2006 carried out "a study concerned with identifying the impact of using available materials on the local environment with the aim of improving the economic situation of the society in Nigeria, by providing a set of training programs based on teaching young people and students a range of crafts and among its results is that the Nigerian society possesses the elements of economic development through the exploitation of a group of agricultural products in the manufacture of creative handicraft products such as pottery and artistic products from traditional pieces of cloth and indicated that the use of materials available in the local environment is a low-cost activity but that it makes an important addition to local communities 
(United Nations Educational, Scientific and Cultural Organization 2006-7).

Ahmad Muhammad Al-Baghdadi (2011) conducted a study aimed at maximizing the opportunities to benefit from waste wood products, which have a regular, irregular and organic engineering body available in Damietta Governorate in wall painting with new plastic formulations for using 3D materials in painting with experimental approaches, to achieve an aesthetic touch to the place, it resulted in the research reaching a classification of the types of wood available in the environment. It turned out that wood waste has wide potentials, the importance of which lies in the shape, and the surface enrichment with various expressive values after using colors or dyes, it came out in the form of individual students' works and group murals in the field of (Mural Painting), and the study recommended stressing the importance of employing waste wood raw materials, because of its multiple potentials and formulations in the field of mural painting, and making use of the waste of other materials and combining them with various wood remnants, to find new plastic formulations.

The study of Farid, Wagdi Rifaat (2012) aimed to discover the use of consumed raw materials in the production of handicrafts based on experimentation, in the production and formation of natural environmental materials, manufactured and available in the learner's environment, and formulating them into handicrafts and making use of them, which leads to a kind of compatibility with The learner, and the curriculum of the study was based on three axes, which are handicrafts, making use of consumed raw materials and the rest of raw materials. The role of the material in the handicraft is the experimentation to create some handicrafts based on consumables. The study concluded that the field of handicrafts accepts everything new in the way used materials are handled and that innovative handicrafts can be produced by making use of experimentation with the plastic capabilities of the consumed materials.

Sally Imad Farouk Al-Sayed Abu Hamila's study (2016) also aimed to develop contemporary plastic formulas for handicrafts by making use of the aesthetic foundations in the abstract nature by developing the formation of combined materials in line with the technical aspects as an entry point for experimentation, by finding plastic formulas and technical methods consistent with the current research, she also used the experimental descriptive approach and reached the use of natural and industrial materials in the plastic merging process to create a handicraft, and recommended using environmental waste to enrich the handicrafts surface through mixing and modern day arts.

Fadl, Yasser Muhammad (2012) emphasized the importance of uncovering plastic handlings for environmental materials in selections from the works of Egyptian and foreign artists, who explained the importance of environmental materials in their artistic creations with the aim of 
achieving approaches in order to develop environmental awareness for students of the Faculty of Specific Education at Assiut University, and opening new horizons for experimentation with local environmental materials - seeking to reach new aesthetic formations in the field of painting, following the descriptive analytical approach with its conceptual framework and experimental method with its applied framework, according to a plan to teach painting by employing aesthetic environmental materials in their work. The study reached several results, the most important of which is the treatment of environmental materials in the art of painting, which helps in the cognitive and cultural awareness of environmental materials among college students, and developing their aesthetic sense by producing innovative paintings carry the character and features of Egyptian culture in Upper Egypt.

Rehab Muhammad Abu Zaid's study (2001) entitled "Creating Wall Hangings with Plastics and Fabrics" deals with the impact of modern artistic trends on fabrics, their types and plastic methods due to their flexibility and ability to be shaped into multiple forms, dealing with the aesthetic values of the fabric material from the combination elements and ways of adding, folding, copying and many other plastic methods that the current research has benefited from. As these arts take the characteristic of interacting with the recipient and the environment, exploiting all the materials of formation and the residues of recycling and trying to understand culture as an essential part of presenting handicraft and adopting it socially to achieve change and community education.

The artist is that maker who wrestles with the material, whether language, color, or otherwise. (Zakaria Ibrahim1976-93), during experimental practices in the field of handicrafts, we find that beauty and utility is a product of human craftsmanship and requires human skill to control the material and possess the aspect of dreams and control the whims of mankind and the likes of that are contemporary aesthetics such as Valerie, Sorbo, Bayer and others, where highlighting the industrial aspect in art as a per formative work requires a lot of efforts. (Zakaria Ibrahim 1979-84) In the light of the development of the language of building creative work and benefiting from it, a research experiment was done to apply handicrafts on a complex work body from cutting fabrics, employing fabric scraps in forming human vocabulary from folk and heritage arts, then using the LUNAPIC program (https://www6.lunapic.com)

Whereas the handicrafts curriculum for the third year of the Faculty of Specific Education Aswan University, the Department of Art Education emphasizes the importance of the student's familiarity with the plastic capabilities of the materials used and the methods of their formation and making use of them in the work of handicrafts characterized by originality and creativity and the importance of linking this with human heritage (folk arts and crafts - African and Indian 
arts, their plastic vocabulary and their symbolic significance), taking into account the implementation of handicrafts the basics of design and its elements through direct thinking of the materials to embody an expressive intellectual principle in a contemporary formative language and through the development of the concept of handicraft. ${ }^{1}$ The research was concerned with a set of artistic features during the experimental practice (Abd Al-Muttalib Amin al-Quraiti 1995-32): (Monther Sameh Al-Ghanum 117-1427)

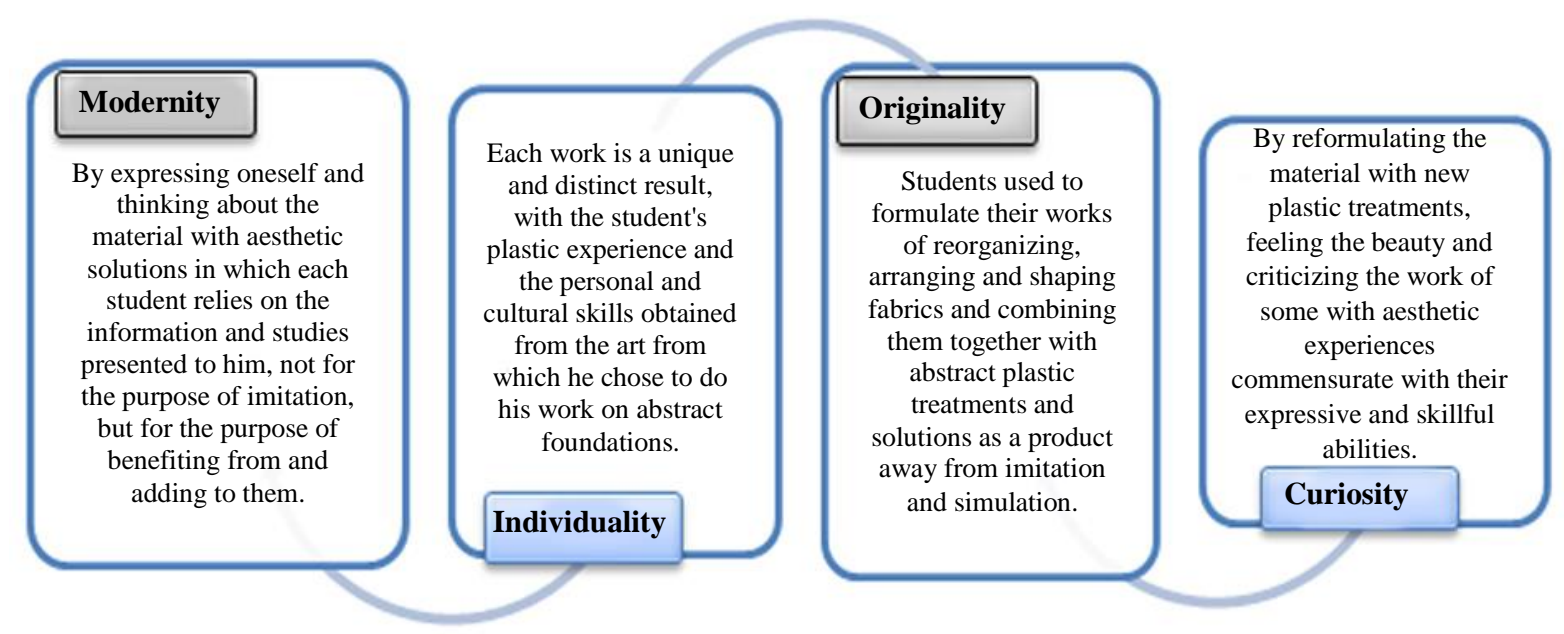

Illustration No. (1)

The research follows the experimental thought as a thought that renews from the formative synonyms in reformulating it in search of formal and formative principles in the field of artefacts, so experimentation means putting the goals into practice according to codified conditions, so that the constants can be controlled and the variables can be defined and limited to a narrow range. According to a protocol of cooperation between Aswan University and the Aswan City Culture Palace within the framework of community partnership, with the aim of presenting ideas that support the fields of small and developmental projects, and confirming the role of artefacts in developing the partnership, the researcher was nominated by the college to implement the idea of benefiting from the rest of the fabrics, which is represented in the "Golden Rule", It is the main focus of industrial ecology by exploiting waste materials "AlNoihi Abdel-Bari (2004-33) in forming human terms from popular and heritage arts. . Hence the role of the Faculty of Specific Education - Aswan University in implementing the vision and mission of the faculty to align the educational outcomes with the requirements of strategic plans for quality and community participation, as there is an urgent need to educate creative

\footnotetext{
${ }^{1}$ Handicraft "A process of self-creation of aesthetic variables based on the exploitation of natural or manufactured raw materials available to the individual, through which he passes and reshapes them by synthesis, using various experiences and information to adapt the materials in accordance with the design and function and take pictures of utilitarian aesthetic products." (1994): "Handicrafts and Contemporary Culture," translated by Muhammad Khalifa Barakat, Cairo, Arab Record Foundation, p. 43.
} 
people and because the college has the privacy of its curriculum systems and components of its courses, it is the closest to offering solutions to environmental problems through community and environmental service programs with the aim of improving the standard of living of local communities, supporting capabilities, developing them, and achieving the idea of small enterprises. From here, the study problem can be specified in the following question:

\section{Research Problem}

1. How can experimental practices be used to create formal and plastic principle in the field of handicrafts?

2. Are there statistical indications to achieve the level of aesthetic performance for designing and shaping a local environmental material with formal and plastic principle for handicrafts?

\section{Research Hypotheses}

1. The possibility of studying the art of collage and the implementation of formal and plastic principle to employ the scraps of fabrics in the formation of human terms from folk and heritage arts. Then using the LUNAPIC program

2. It is possible to take advantage of the pre-engineering design of the remnants of fabrics in the development of terms and designs suitable for the implementation of handicrafts.

3. There is a statistically significant relationship between the degree of acceptance and success of the executed works and the extent of achieving the design elements.

4. There is a statistically significant relationship between the degree of acceptance and success of the executed works and the extent of achieving the level of aesthetic performance for forming fabric scraps.

5. There is a statistically significant relationship between the degree of acceptance and success of the executed works and the extent to which they achieve aesthetic values.

\section{Research Objective}

1. Deepening the role of handicrafts as a course in the Faculty of Specific Education, to be used in the development of the environment and society as a formative principle for the implementation of handicrafts.

2. Finding multiple applied approaches to handicrafts in solving one of the environmental problems for the safe disposal of waste from textile factories and ateliers in Aswan.

3. Take advantage of experimental practices to create formal principles using computer programs, the LUNAPIC program to find plastic solutions to design a functional, utilitarian, aesthetic handicrafts by presenting a different intellectual vision in terms of the diversity of different methods of expression in a way that the student finds a way of 
expression that is commensurate with his abilities and skills, taking into account here the economic content of the handicrafts.

\section{Research Importance}

1. Making use of the scraps of fabrics as a plastic mediator through experimental practices to create formal and plastic principles in the field of handicrafts.

2. The research tries to establish a new trend that depends on completing a connection among modern arts and making use of it in implementing a handicraft that relies on executive solutions that are commensurate with the majority, to link and complement the theoretical and operational aspects.

3. Research contributes to benefiting from local environmental materials (textile scraps) through recycling and there are many among the benefits of recycling waste, the most important of which are:

A. It protects the natural resources.

B. Reduces waste.

C. Finding new job opportunities.

D. Nature protection and economizing raw materials, as it helps in sustainable development as an issue in the economy, society and the environment.

4. Helping officials in ready-made clothes factories to obtain a new strategy in dealing in a technical and economic way with the garment waste accumulated with them.

Environmental Scraps

(Defective Parts)

\begin{tabular}{c|c} 
Textile & $\begin{array}{c}\text { Sewing and } \\
\text { Detail Remnants }\end{array}$
\end{tabular}

Remnants of Survey Stage
Remnants of Dyeing and Finishing

Sources of Waste and Fabric Scraps in Ready-Made Clothes Factories 


\section{The Stages Required for handling Waste and Remnants}

Figure (4) shows the sequence of stages that the remnants go through until we get textile products of a high level of quality, and these processes begin to prepare the remnants and waste until they become prepared raw materials for operations, and it is worth noting here the importance of the preparatory stages in showing the value of these remnants, as they differ completely after performing these operations.

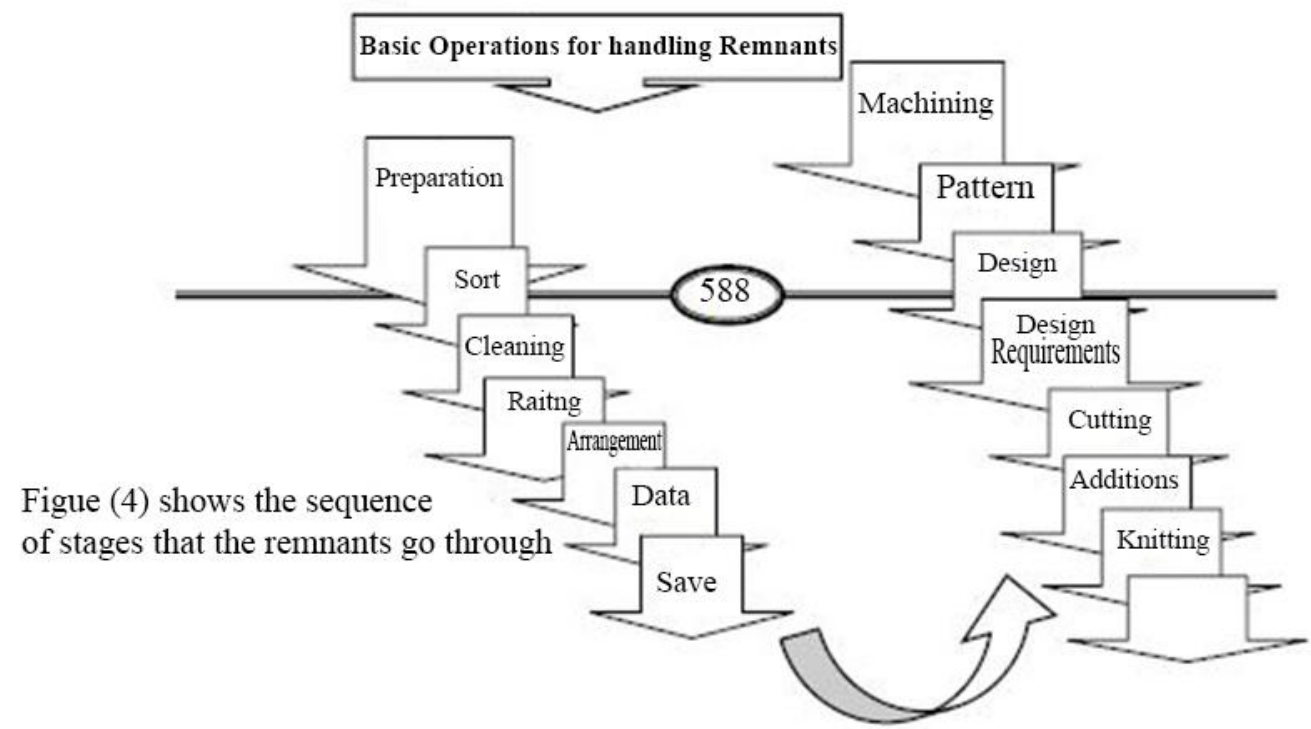

Illustration No: (2) (Zainab Ahmed Abdel Aziz 2011-25)

1. Research Tools: Designing an evaluation card for the handicrafts, the outcome of the research experience, and presenting it to the refereed professors, which is a set of criteria that measure the judgment on the handicrafts prepared by the researcher.

\section{Research Limits:}

- Human Borders: The work of students of the Faculty of Specific Education, Third Year - Department of Art Education - Aswan University.

- Thematic boundaries: Studying the art of collage and how to use the scraps of fabrics in forming human terms from folk and heritage arts, then using the Scribble Art program to create formal principle for the handicrafts.

\section{Research Terms}

A practical Achievement Test: A structured procedure to determine how much students have learned in a subject in light of the specific objectives benefiting from it in improving learning methods, and contributes to proficiency in planning, controlling implementation and evaluating achievement (Ali Ahmed and Ahmad Muhammad 2004-43) and this what the student gets from skills and abilities, and mastering them through creative use of materials available in the environment. 
Experimentation: It is a method in artistic performance and a creative activity that may be in a group of layouts that precede the completion of the handicrafts in search of different aspects or new plastic attachments as a result of the vision of the shape, and it may be in showing the different aesthetic visions of the subject that prepares the mind and the sense for the plastic and creative practice in search of multiple and different solutions either within the framework of the present artist or as a result of the artist passing through previous artistic experiences, therefore, introducing new attachments to the formations and new arrangements (Huda Ahmed Zaki Al-Sayed 1979-27).

Handicrafts: (Suleiman Mahmoud 1982-32) is one of the areas of art practices, which provides an individual with opportunities for expression in one of two forms:

The First: The completion of works that have utilitarian functions in addition to their technical value, using the basis of design.

The Second: making things with a purely aesthetic purpose, including the three-dimensional stereoscopic and the two-dimensional flat.

Research Methodology: The research follows the descriptive and quasi-experimental approach through two frameworks:

\section{The Conceptual Framework}

\section{First: For the Student}

1. Developing the abilities of imitation and thinking through the implementation of a teaching unit in the handicrafts course of the third year.

2. Development of thinking and synthesis abilities "to provide the student with the ability to visualize a mental vision of the figure as a whole according to his imagination and thinking." (Ghada Mustafa Rashwan 2014-137).

3. Development of imagination and mental perception capabilities to suit the techniques used in formulation.

The field of handicrafts helps the growth of capabilities and skills through experimentation with the use of various materials through which new experiences are explored through the sincere interaction between the artist and the materials he deals with experimentally during the implementation of the handicrafts. Handicrafts give great refreshment to the mind, as well as the recovery caused by large handicrafts, and the basic importance of handicraft products for us as users is that they are considered a means and an end, as it is available in dynamic work and quality (Sionide Merry Robertson 1964 -32) and colors with light and the shadows it causes in embodying and expressing shapes, so the art student will express in this type of design, and learn about its plastic validity, its sensory and compositional properties, and its adaptation to 
plastic ideas, the adaptation of ideas to the formative data of the raw material, which constitutes an important artistic and educational role, which will lift the economic burden that costs the art practitioner by using the usual raw materials and will save the effort and time spent in artistic production.

\section{Second: Study Procedures}

Study Method: Using the quasi-experimental method, where two groups were selected, one experimental (20 students) and the other control (20 students).

Study Sample: The study sample was chosen by the intentional method from the third year students of the Faculty of Specific Education - Aswan University 2019, the two sections were distributed randomly into two groups, one control and other experimental, and thus the study sample consisted of (40) students, distributed among groups as shown in Table (1):

Table (1) Distribution of Students of the Study Sample over the two Study Groups

\begin{tabular}{|l||l||l||l||}
\hline $\begin{array}{l}\text { Faculty of Specific } \\
\text { Education }\end{array}$ & Method & Number of Students & The Total Number \\
\hline \multirow{2}{*}{$\begin{array}{l}\text { Department of Art } \\
\text { Education }\end{array}$} & Experimental & 20 & 20 \\
\cline { 2 - 4 } & Control & 20 & 20 \\
\hline \hline Total & $\mathbf{4 0}$ & $\mathbf{4 0}$ \\
\hline
\end{tabular}

Study Tools: The researcher prepared a test tool for practical application, as she used the performance-based evaluation strategy (the practice of forming course techniques), while the evaluation tool was a numerical assessment scale, and the following is a description of that:

\section{Practical Application Test}

- The researcher divided the work into 4 weeks for the formation project for the art works according to the description of the technical works decision (2), and she reviewed some studies that explained how to set standards for the use of available materials in the handicrafts, then developed a numerical scale for the assessment to measure the effect of using the materials available in the local environment of the city of Aswan on the achievement of students of the Department of Art Education in the course of handicrafts (2), to achieve the cognitive, skill and emotional goals of the course in the collage with the scraps of fabrics and the use of synthesis materials, as the numerical scale for each skill included (10) paragraphs, each one including a scale of (1--10 degrees), so the total of each paragraph is (10) degrees.

- After that, the degrees of each practice were collected, whether practical, plastic and aesthetic techniques to enrich the manual work, then they were combined to become 
the final degree of (100) degrees, as the evaluation was based on the student's ability to employ materials, techniques, formal and color relations, their suitability to the nature of the applied handicraft, the general composition and degree of mastery and innovation for the produced work, then being able to use it with the LUNAPIC program to employ it in a formative and formal basis with other materials in the field of handicrafts.

- Validity of the Test by Practical Application: It is a numerical evaluation scale to verify the validity of the test in practical application, and it consists of (10) paragraphs, each paragraph contains a scale of assessment (1-10 degrees) equal to each mark and the extent of its compatibility with the objectives of the description applied to the course. It was presented to a panel of judges consisting of (8) specialists in the field of art education in general and handicrafts, and their opinion was taken on the appropriateness and clarity of the phrases for evaluation, and the extent to which these standards represented and included the content of the four encounters, which are: design, collage with fabrics, implementation of each piece in the program by choosing 1 or 2 of its applications and the possibility of implementing it with other materials with different plastic capabilities such as wood, oil colors, charcoal pens, leather, plastics.. all materials synthesis study by (12) practical hours for the study procedures, the main concepts, ideas, materials, techniques and the program were determined, and the students' ability to use it was ascertained by preparing laboratories for the operation and the computer lab and then following up the implementation.

- The stability of the tool was confirmed by applying it to an exploratory sample from outside the study sample, who are (20) students in the third year, as I presented the educational material to them, in cooperation with the assistant professor who supervises me on the work of course P. Reham Gharib and under my supervision, she applied the practical test and reapplied it after two weeks in forming human vocabulary from folk and heritage arts, then performing the necessary statistical treatments and using the Pearson correlation coefficient, the reliability coefficient of the test by the method of applying and re-applying the test was (0.86).

- Equalization of groups of technical skills, arithmetic averages and standard deviations were extracted for various formative practices according to the group variable (experimental, control). To verify the parity of groups, and to clarify the statistical differences among the arithmetic averages, the "T" test was used, and the table below (2) illustrates this; 
Table (2): Arithmetic Means, Standard Deviations, and Tests according to the Group Variable on Technical Skills in the Pre-Test

\begin{tabular}{|c|c|c|c|c|c|c|c|}
\hline $\begin{array}{l}\text { Technic } \\
\text { al Skill }\end{array}$ & Group & $\begin{array}{l}\text { Numb } \\
\text { er }\end{array}$ & $\begin{array}{l}\text { Arithmet } \\
\text { ic Mean }\end{array}$ & $\begin{array}{l}\text { Standar } \\
\text { d } \\
\text { Deviati } \\
\text { on }\end{array}$ & $\begin{array}{l}\text { "T" } \\
\text { Valu } \\
\text { e }\end{array}$ & $\begin{array}{l}\text { Degree } \\
s \quad \text { of } \\
\text { Freedo } \\
\text { m }\end{array}$ & $\begin{array}{l}\text { Statistical } \\
\text { Significan } \\
\text { ce }\end{array}$ \\
\hline \multirow[t]{2}{*}{ Design } & $\begin{array}{l}\text { Experimen } \\
\text { tal }\end{array}$ & 20 & 6.45 & 1.791 & \multirow[t]{2}{*}{080.} & \multirow[t]{2}{*}{38} & \multirow[t]{2}{*}{937.} \\
\hline & Control & 20 & 6.50 & 2.141 & & & \\
\hline \multirow{2}{*}{$\begin{array}{l}\text { Fabric } \\
\text { Collage } \\
\text { Works }\end{array}$} & $\begin{array}{l}\text { Experimen } \\
\text { tal }\end{array}$ & 20 & 4.80 & 1.576 & \multirow[t]{2}{*}{096.} & \multirow[t]{2}{*}{38} & \multirow[t]{2}{*}{924.} \\
\hline & Control & 20 & 4.85 & 1.725 & & & \\
\hline \multirow{2}{*}{$\begin{array}{l}\text { Formal } \\
\text { and } \\
\text { Formati } \\
\text { ve } \\
\text { Principl } \\
\text { e of the } \\
\text { Progra } \\
\text { m (1) }\end{array}$} & $\begin{array}{l}\text { Experimen } \\
\text { tal }\end{array}$ & 20 & 3.40 & 1.667 & \multirow[t]{2}{*}{655.} & \multirow[t]{2}{*}{38} & \multirow[t]{2}{*}{517.} \\
\hline & Control & 20 & 3.75 & 1.713 & & & \\
\hline \multirow{2}{*}{$\begin{array}{l}\text { Formal } \\
\text { and } \\
\text { Formati } \\
\text { ve } \\
\text { Principl } \\
\text { e of the } \\
\text { Progra } \\
\text { m (2) }\end{array}$} & $\begin{array}{l}\text { Experimen } \\
\text { tal }\end{array}$ & 20 & 2.60 & 1.095 & \multirow[t]{2}{*}{291.} & \multirow[t]{2}{*}{38} & \multirow[t]{2}{*}{773.} \\
\hline & Control & 20 & 2.70 & 1.081 & & & \\
\hline \multirow{2}{*}{$\begin{array}{l}\text { Pre- } \\
\text { Holistic } \\
\text { Test }\end{array}$} & $\begin{array}{l}\text { Experimen } \\
\text { tal }\end{array}$ & 20 & 17.25 & 5.320 & \multirow[t]{2}{*}{300.} & \multirow[t]{2}{*}{38} & \multirow[t]{2}{*}{766.} \\
\hline & Control & 20 & 17.80 & 6.229 & & & \\
\hline
\end{tabular}


It is clear from the above table that there are no statistically significant differences $(a=0.05)$ in the arithmetic means of skills according to the group variable (experimental, control), which indicates parity between groups on the pre-test.

- The control group and the experimental group were identified, where the practices were explained and implemented for the control group in the traditional way, with some papers and how to implement them by cutting or abstraction so that they practice collage with what they know from previous information, while in the experimental group the students were provided with all the materials and tools available in the environment of Aswan, from textile shops, tailoring ateliers, and the garment factory.

- About a week before starting the experiment, it was used in the process of explaining the theoretical and training practices, so: scraps of fabrics of various colors, textures and materials, adhesive, chassis, metal strips, hammering tools, models of women and portraits of different personalities from different parts of the world, Mexico, upper Egypt, gypsy, Royal... in the formation of human terms from folk and heritage arts, colors, scalpels, gloves, needles, cotton and silk threads, beads and other materials for synthesis were provided.

- A power point presentation was viewed explaining and clarifying the idea of collage for a portrait design to clarify the idea for them to start implementing and confirming that the handicraft done will be a new formative principle that came after breaking the artistic rules in different schools from impressionism and brutality to Dada, abstraction, cubism and surrealism. The meeting was held with the assistant teacher to explain the method of implementation and the different practices that will be implemented through the different backgrounds and the varied division among engineering, soft and organic as in the following models Figure (4: 8)
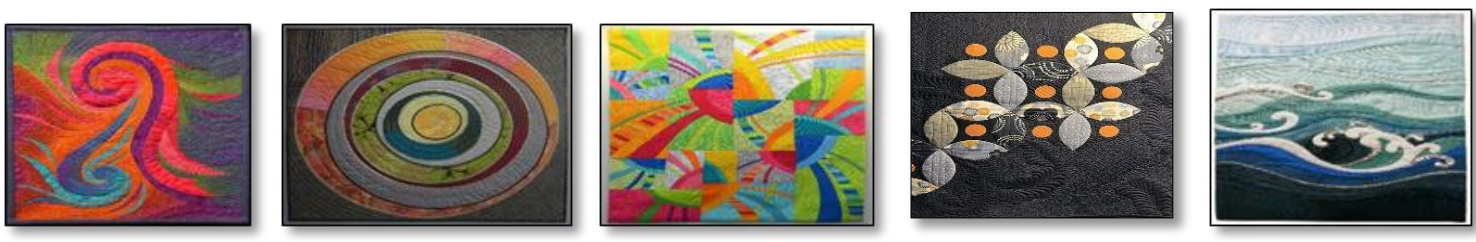

Figure (4: 8) Different background models for the diverse division among geometric, soft and organic

Which also contained a great deal of expressionism, and among the various abstract trends, up to the pure geometric abstraction and away from any simulated intent, the multiplicity of directions and formulas of plastic design for formal and plastic principles by presenting a different intellectual vision in terms of the diversity of the different ways of expression in a way out for the student to find a method of expression that is appropriate with his abilities and 
skills, and I have taken into account here the economic content of handicrafts (Joseph Muller, 1988-54). In order to accomplish the handicrafts, we must follow the following:

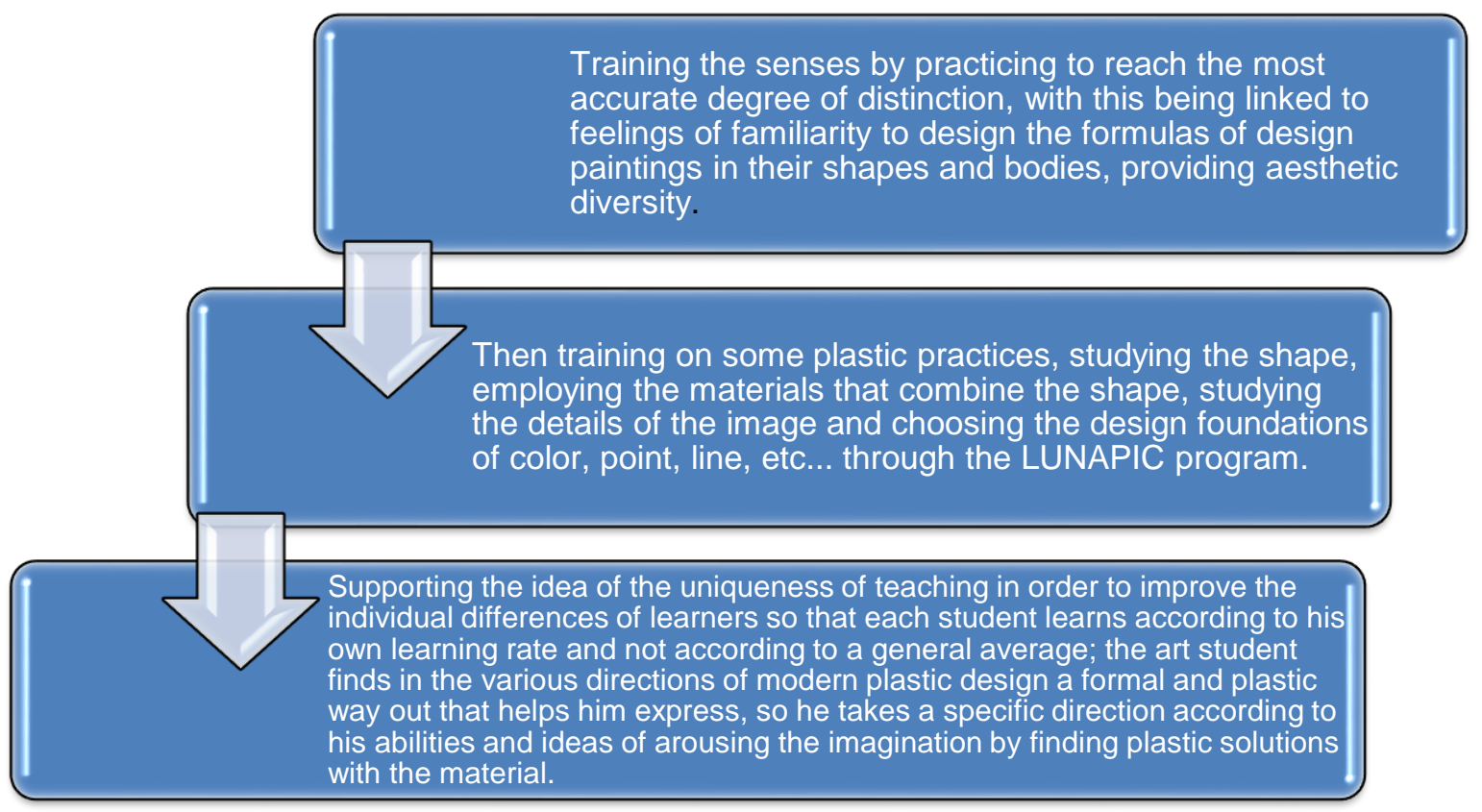

Illustration No: (3)

\section{Third: The Indicative Techniques used}

Students were also instructed to take into account the foundations and criteria upon which the construction of the manual work design depends by analyzing the intellectual and formative principles of the synthesis art (Amy Demp2002) -32) using fabric remnants and waste from the Aswan environment. The experimental intellectual direction depends on intellectual fragmentation and an artistic constructive restructuring, where students use geometric shapes of circles, squares, and rectangles and place them as groups superimposed on top of each other and with regular repetition in different positions in the geometry form space to illustrate "an aesthetic vision consisting of repetitive rhythms of some geometric shapes made of reinforced cloth" to work the mind in front of things and focus with a cognitive vision"(Mohamed Salah El-Tohamy 2006 -38). As in the following experiments (Figure 9: 13).
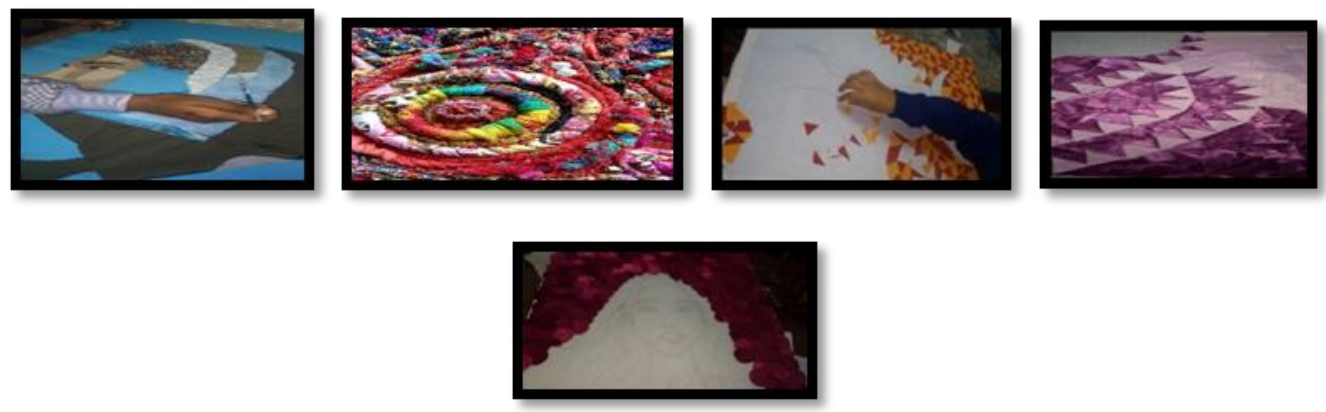

Figure (9:13) Plastic Experiments in implementing the Background of the Artistic Preoccupation with Different Plastic Techniques 
- Giving new and innovative solutions and methods to plastic visions, combining different fields of art, such as sculpture, painting, works, etc., to express rebellion against traditional ideas in art.

- Combining the raw materials of synthesis, which helps to intensify the plastic expression and serves the content of the form to form a handicraft with a multiplicity of materials from fabrics, metals, buttons, beads and raw materials for synthesis in search of plastic intellectual dimensions that achieve richness for its surface.

- - The meeting was held with the experimental group, and the implementation plan and practice were clarified using technology factors (raw materials - implementation methods - tools). Models of different designs were presented for facial analysis to find solving formation.

- Then some types of remains of fabrics were shown and identifying their types, then choosing what is appropriate from the rest of the fabrics (light - heavy - plain textured), and divided the experimental group into four groups, where each group was asked to accomplish the specific tasks and goals and to implement the technical methods appropriate to the raw fabrics.

\section{Fourth: Experimental Technical Practices}

Layered folding and cutting, and the use of the running stitch, one of the embroidery stitches, to obtain the plastic technique required for doing of the work.

\section{Methods of embossing Fabrics with White Glue}

Embodiment using the template and achieving the three dimensions in the work by stretching the cloth on the previously prepared template for that, then a quantity of liquid white glue is poured on it and left until it hardens, which gives the cloth a kind of toughness and durability that makes it retain the shape it is embodied on. .
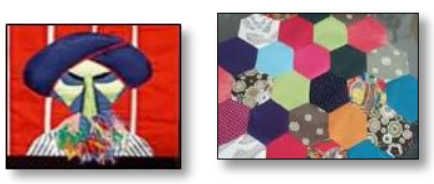

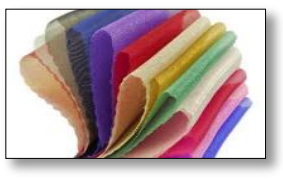

Figure (14:17)

Khayamia (Patchwork): It is the art of patching up or recycling the remnants of fabrics and turning them into (paintings, bedding, children's games, curtains). It has ancient roots spread all over the world and also has different images. "http://sayidati.banoata.net"

Cutting ribbons and create decorative circular units in the form of prominent roses. 

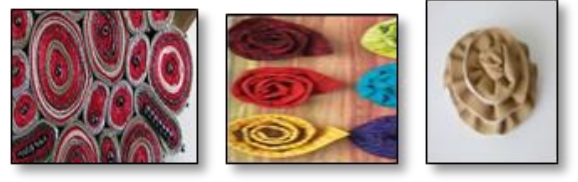
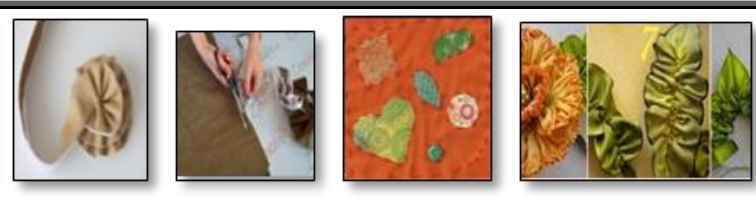

Figure (18:25)

The embroidery and folding method (Smocking) is a technique that gives a sense of varied texture by folding the cloth with different methods and fixing it on different dimensions using different types of threads and various methods of embroidery. Often this style appears in geometric shapes that create depths through protruding and recessed folds of fabric

Bending Method: Is to join something together or roll it together on top of each other (Susan Gerges 2013-23)
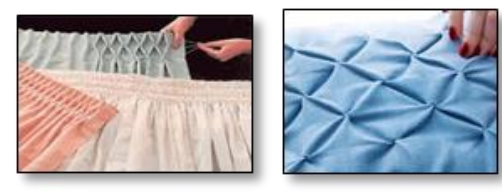

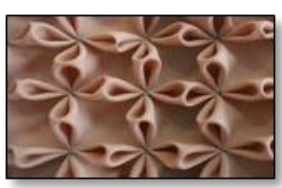

Figure (30:26)
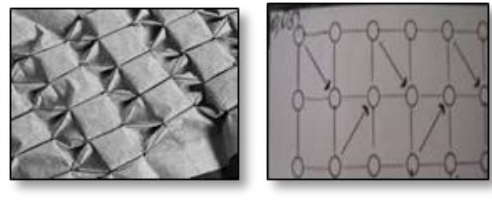

Regular Folds: They are folds on the cloth and sew it to a certain extent and repeating that process in a monotonous manner that creates a certain texture.
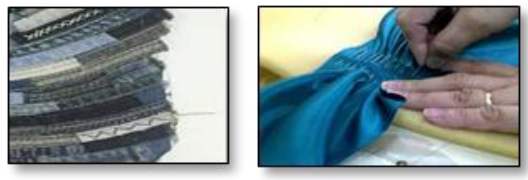

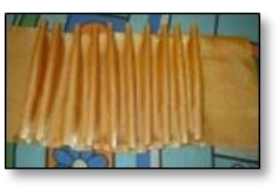

Figure (31:35)
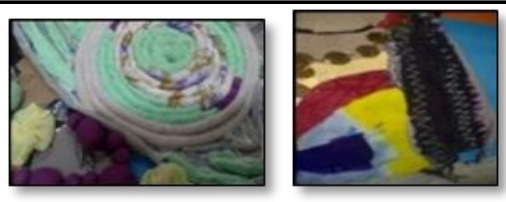

Patchwork Method: Depends on the collection of scraps of fabrics closely together, fixed with each other by hand embroidery methods and machines. These scraps may be small in size, so it is called the (mosaic) method due to their small size and their close approaches to each other. And we can put different geometric areas from various fabrics to collect them together to give large areas and then put on each other to produce free shapes by fixing them with embroidery, and this method depends on the compatibility and homogeneity of the chosen fabric scraps in terms of texture or color, which gives richness to the handicraft.

Lace Ribbon Trim Applique: A method of filling large areas of fabrics, as it is a pre-woven area, whether embroidered or perforated, to enrich the general surface of the handicrafts.

Implement buttons and circular tufts solutions.
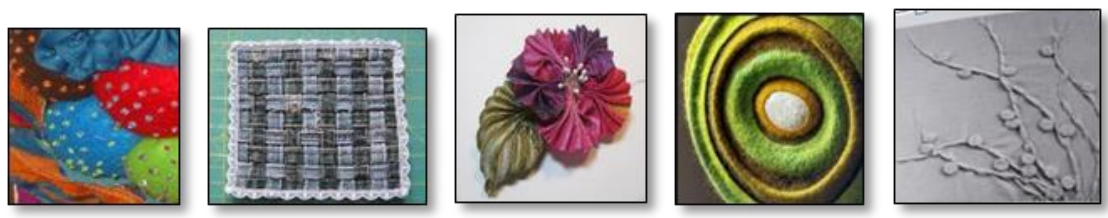

Figure (36:40) 
Open Work and Faggoting: It is a type of embroidery in which the horizontal threads of the cloth (the weft) are pulled together with the remaining vertical lines (the warp) in the form of bundles, resulting in a perforation in the flat cloth.
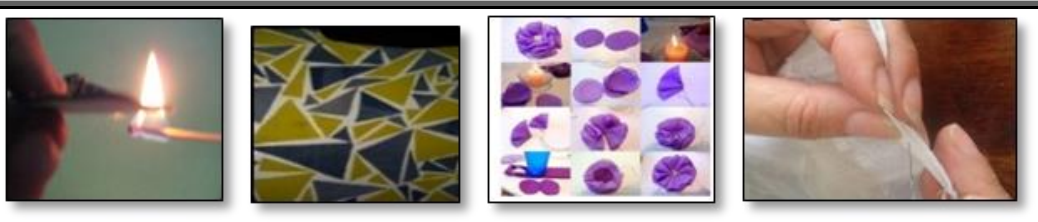

Figure (41:44)

Burning and Smoking: This method has been used since the times of the Pharaohs in fumigation of mummies' shrouds. It occurs by exposing the fabrics to smoke and rising fumes for periods of time, and it darkens the color of the fabric, and it was used in natural linen fabrics. Currently, it's used in industrial materials, especially fencer able fabrics, by burning their edges and the vacuum can be used for small spaces. https://www.scientificamerican.com/arabic/articles/news/science-of-embalming-is-historically

Slopwork: It is a method of perforation on weft and warp fabrics, i.e. woven fabrics with clear texture, and is carried out by removing the weft threads and leaving the warping threads, which gives a feeling of shading in the parts of the design.
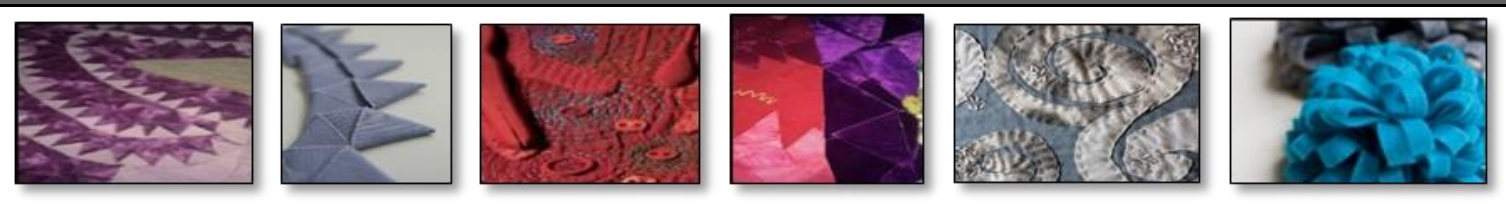

Figure (45:50)

Embroidery Style: Is the decoration of fabric woven by sewing needles using colored threads.
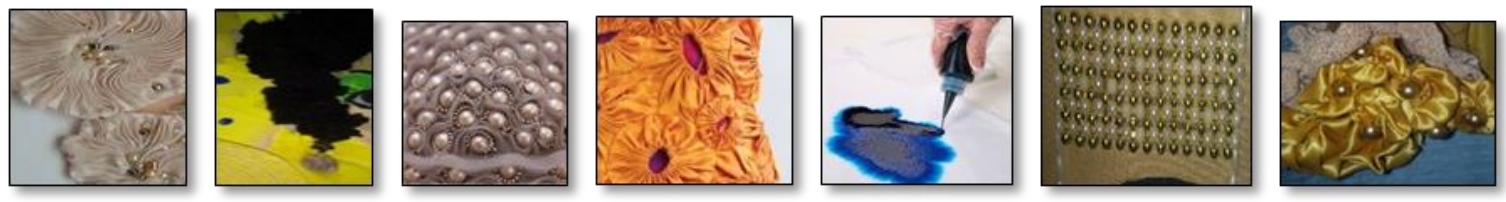

Figure (51:57)

Bead Work: It consists of fixing types of beads or buttons as additional accessories and fixed by needle work.

Combination: Synthesis was defined as "an act intended to use materials that are proportional to each other in a single work of art, with which the harmony among the materials is completed to enrich the work of art" (Fatima Abdel-Aziz Al-Mahmoudi 1988-12).

Pouring Acrylic Style: Coloring on the surface of fabrics by pouring colors directly to give color gradients.

- The roles were distributed to the experimental group students, and the roles of the rest of the groups were clarified after the implementation. They painted the work carried out and then used the scribble art program, to choose which materials that could be used in another lesson with materials such as leather, buttons, stones, colors, $2 \mathrm{~d}$ or $3 \mathrm{~d}$, so we 
started by introducing a topic, and presenting its own goals, whether by the experimental group or the control one, in preparation for applying it in the courses of painting, drawing, ceramics and ... so that there is a link among the courses and each other.

- Follow the continuous guidance and direction of students during the implementation and practice of techniques, and listen to various questions through different strategies according to the description, including dialogue, discussion and cooperative learning to reach the results of the implementation of the work in line with the goals to be achieved, and to ensure compliance with the directions and the extent of students' interaction with the materials available in the Aswan environment for the experimental group, as well as for the control one, after the end of the experiment, the two groups were subjected to a post-test.

\section{Fifth: Lunapic Applications}

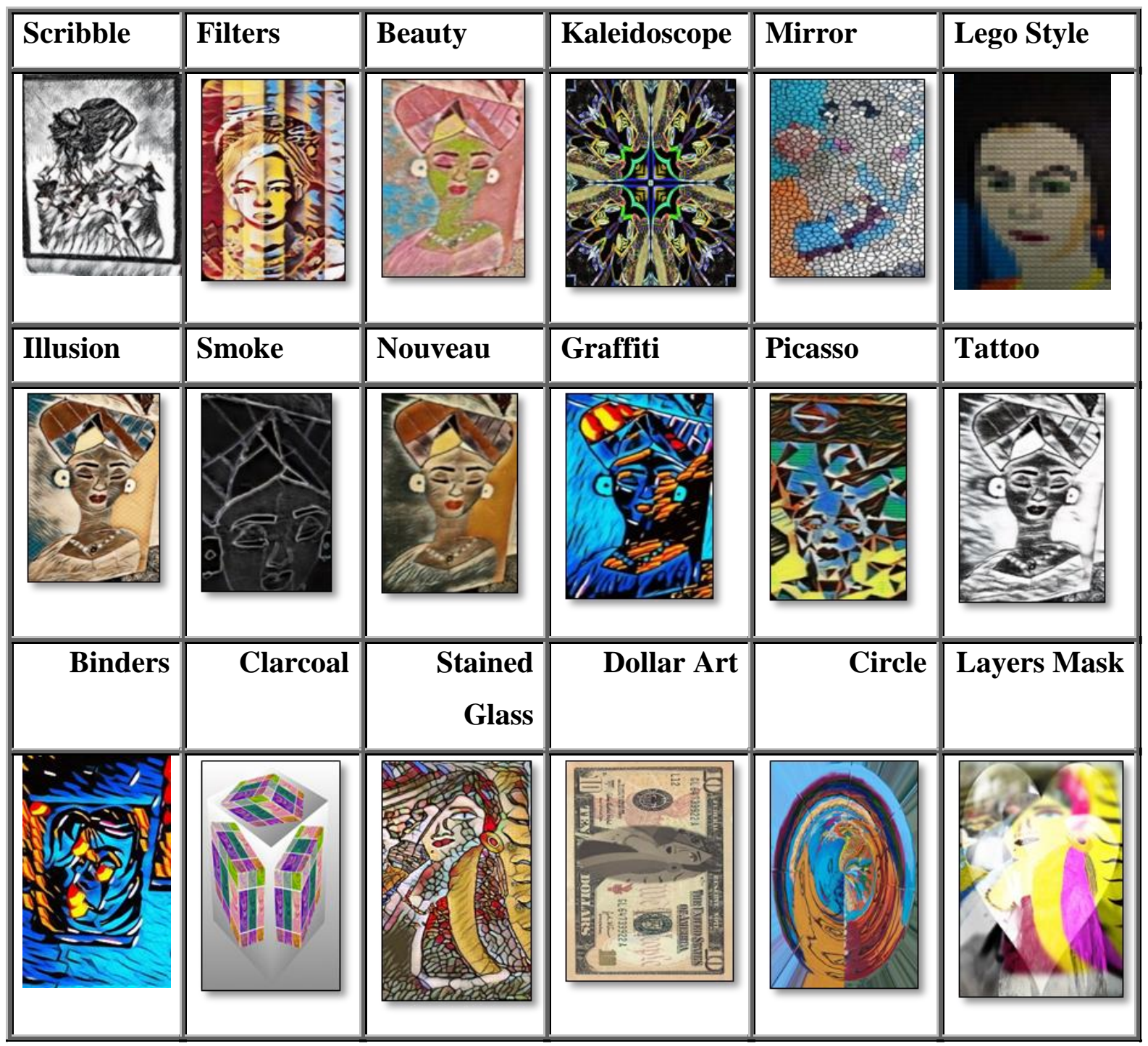

Figure (58:75) 


\section{Executive Program Applications}

After forming the pictures of the handicrafts executed from the scraps of fabrics on the LUNAPIC program, formal and plastic inputs were made for artistic products in the form of a decorative supplement, a cup, a book cover, a jewelry pendant, or in the form of a children's toy, and prices were set on them to start displaying them on a website that students earn from of presenting their formal and plastic principle.
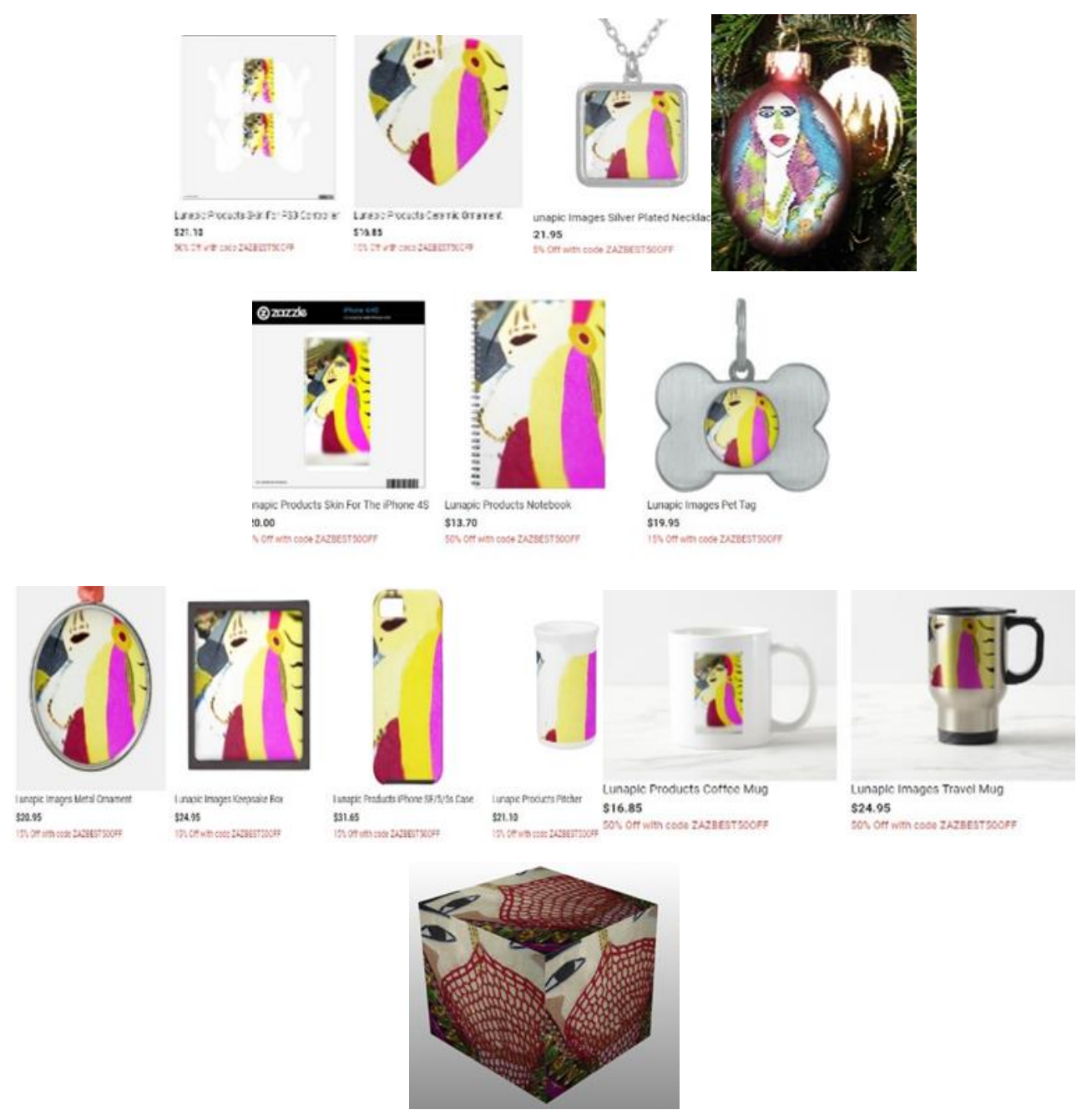

Formal Principles for Artistic Products (Figure76:89)

\section{Statistical Analysis}

The SPSS program was used for statistical analysis, and the following statistical treatments were used to answer the following:

1. Arithmetic means, standard deviations, and (T) test, to check the equivalence of groups on the pre-achievement test.

2. Arithmetic means, standard deviations, and (T) test, to answer the study questions.

- The results of the dimensional tests were analyzed and the arithmetic means and standard deviations were presented - and the following shows the results of the study: 
Table (3): Arithmetic means, standard deviations, and "T" test for the impact of the teaching method on the performance of the members of the basic study sample in the post test

\begin{tabular}{|c|c|c|c|c|c|c|c|}
\hline $\begin{array}{l}\text { Technic } \\
\text { al Skill }\end{array}$ & Group & $\begin{array}{l}\text { Numb } \\
\text { er }\end{array}$ & $\begin{array}{l}\text { Arithmet } \\
\text { ic Mean }\end{array}$ & $\begin{array}{l}\text { Standar } \\
\text { d } \\
\text { Deviati } \\
\text { on }\end{array}$ & $\begin{array}{l}\text { "T"T" } \\
\text { Valu } \\
\text { e }\end{array}$ & \begin{tabular}{|l|}
\multicolumn{2}{|c|}{ Degree } \\
$\mathrm{s} \quad$ of \\
Freedo \\
m
\end{tabular} & $\begin{array}{l}\text { Statistical } \\
\text { Significan } \\
\text { ce }\end{array}$ \\
\hline \multirow[t]{2}{*}{ Design } & $\begin{array}{l}\text { Experimen } \\
\text { tal }\end{array}$ & 20 & 9.15 & 1.040 & \multirow[t]{2}{*}{$\begin{array}{l}2.15 \\
8\end{array}$} & \multirow[t]{2}{*}{38} & \multirow[t]{2}{*}{037.} \\
\hline & Control & 20 & 7.95 & 2.259 & & & \\
\hline \multirow{2}{*}{$\begin{array}{l}\text { Fabric } \\
\text { Collage } \\
\text { Works }\end{array}$} & $\begin{array}{l}\text { Experimen } \\
\text { tal }\end{array}$ & 20 & 8.65 & 1.089 & \multirow[t]{2}{*}{$\begin{array}{l}2.90 \\
0\end{array}$} & \multirow[t]{2}{*}{38} & \multirow[t]{2}{*}{006.} \\
\hline & Control & 20 & 6.90 & 2.469 & & & \\
\hline \multirow{2}{*}{$\begin{array}{l}\text { Formal } \\
\text { and } \\
\text { Formati } \\
\text { ve } \\
\text { Principl } \\
\text { e of the } \\
\text { Progra } \\
\text { m (1) }\end{array}$} & $\begin{array}{l}\text { Experimen } \\
\text { tal }\end{array}$ & 20 & 7.20 & 1.399 & \multirow[t]{2}{*}{$\begin{array}{l}2.01 \\
6\end{array}$} & \multirow[t]{2}{*}{38} & \multirow[t]{2}{*}{050.} \\
\hline & Control & 20 & 5.95 & 2.395 & & & \\
\hline \multirow{2}{*}{$\begin{array}{l}\text { Formal } \\
\text { and } \\
\text { Formati } \\
\text { ve } \\
\text { Principl } \\
\text { es of the } \\
\text { Progra } \\
\text { m (2) }\end{array}$} & $\begin{array}{l}\text { Experimen } \\
\text { tal }\end{array}$ & 20 & 6.30 & 1.342 & \multirow[t]{2}{*}{$\begin{array}{l}4.15 \\
9\end{array}$} & \multirow[t]{2}{*}{38} & \multirow[t]{2}{*}{000.} \\
\hline & Control & 20 & 4.00 & 2.077 & & & \\
\hline \multirow{2}{*}{$\begin{array}{l}\text { Post- } \\
\text { Holistic } \\
\text { Test }\end{array}$} & $\begin{array}{l}\text { Experimen } \\
\text { tal }\end{array}$ & 20 & 31.30 & 4.566 & \multirow[t]{2}{*}{$\begin{array}{l}2.96 \\
7\end{array}$} & \multirow[t]{2}{*}{38} & \multirow[t]{2}{*}{005.} \\
\hline & Control & 20 & 24.80 & 8.667 & & & \\
\hline
\end{tabular}


The previous table shows the following:

1. There are statistically significant differences between the control group and the experimental group for the skill of design work, where the level of significance was (0.037) which is less than (0.05), and the differences were in favor of the experimental group.

2. There were statistically significant differences between the control group and the experimental group for the skill of fabric forming for the art of collage, where the level of significance was (0.006) which is less than (0.05), and the differences were in favor of the experimental group.

3. There are statistically significant differences between the control group and the experimental group for the formal and formative skill (1) of the program LUNAPIC, where the level of significance was (0.05), which is equal to (0.05), and the differences were in favor of the experimental group.

4. There are statistically significant differences between the control group and the experimental group for the formal and formative skill (2) of the program LUNAPIC, where the level of significance was (0.000) which is less than (0.05), and the differences were in favor of the experimental group.

5. There were statistically significant differences between the control group and the experimental group for all plastic practices, where the level of significance was (0.005) which is less than (0.05), and the differences were in favor of the experimental group.

\section{Results and Discussion}

- The results of this study showed the total number of the four skills, the skill of design work, the skill of forming fabrics, the art of collage, the skill of formal and formative principle (1), (2) of the LUNAPIC program. There are clear statistically significant differences in the achievement results in favor of the experimental group at the expense of the control group, in terms of skills, we find that the skill of paper collage works came with statistically significant differences between the control group and the experimental group in favor of the experimental group, and all skills were topped, as students' good knowledge of this material, techniques and methods of forming the program on a daily basis, which made it easier for them to experiment and excel in it.

- The presence of statistically significant differences between the control group and the experimental one for the skill of fabric shaping, for the art of collage, in favor of the experimental group, as I made it clear that the scraps of fabrics as waste have wide 
potentials not only related to the shape, and to create multiple and varied surface values. We also find that there are statistically significant differences between the control group and the experimental one for the skill of formal and formative principle of the program LUNAPIC in favor of the experimental group, which emphasized the use of the technical and aesthetic data of the raw fabrics, which leads to the opening of wider horizons in the field of handicrafts in general and for learners in particular.

- The existence of statistically significant differences between the control group and the experimental one for all four skills, and in the total these differences were in favor of the experimental group, which relied on experimenting with a collection of raw fabrics in the environment of Aswan, which contributed to the learning outcomes of the handicrafts course (2) based on the evaluation of their executed plastic works, as learning through the use of materials available in the local environment made the student find solutions to provide raw materials Under the financial circumstances in which the prices of technical formation materials are high, which helped to implement different experimental and technical practices on the members of the experimental group, so it had an active role in developing their abilities, learning with understanding and perception, and acquiring the knowledge and skill foundations to deal with them. They acquired direct sensory experiences and skills through direct thinking about materials, methods of forming fabrics, appropriate tools and experimenting them, interacting with them in accordance with their tendency and needs, and using them in a way that suits their skills and the courses of the third year, which contributed to increasing their motivation and the desire to learn through coexistence and interaction, which generated the love of work, and helped form positive trends and created an exhibition at the Aswan Culture Palace to display their works and ideas, which they donated to the residential units at the university's common room to faculty members after the exhibition as an aesthetic touch from them and a continuous and sustainable imprint of them with an aesthetic interest for their university and their environment.

Figure $(90,197)$ Shots from an Exhibition "She is in Their Eyes" of the Third year at Aswan Cultural Palace Executed Handicrafts and their Details - Collections at the Teaching staff's Common Room in Aswan University 


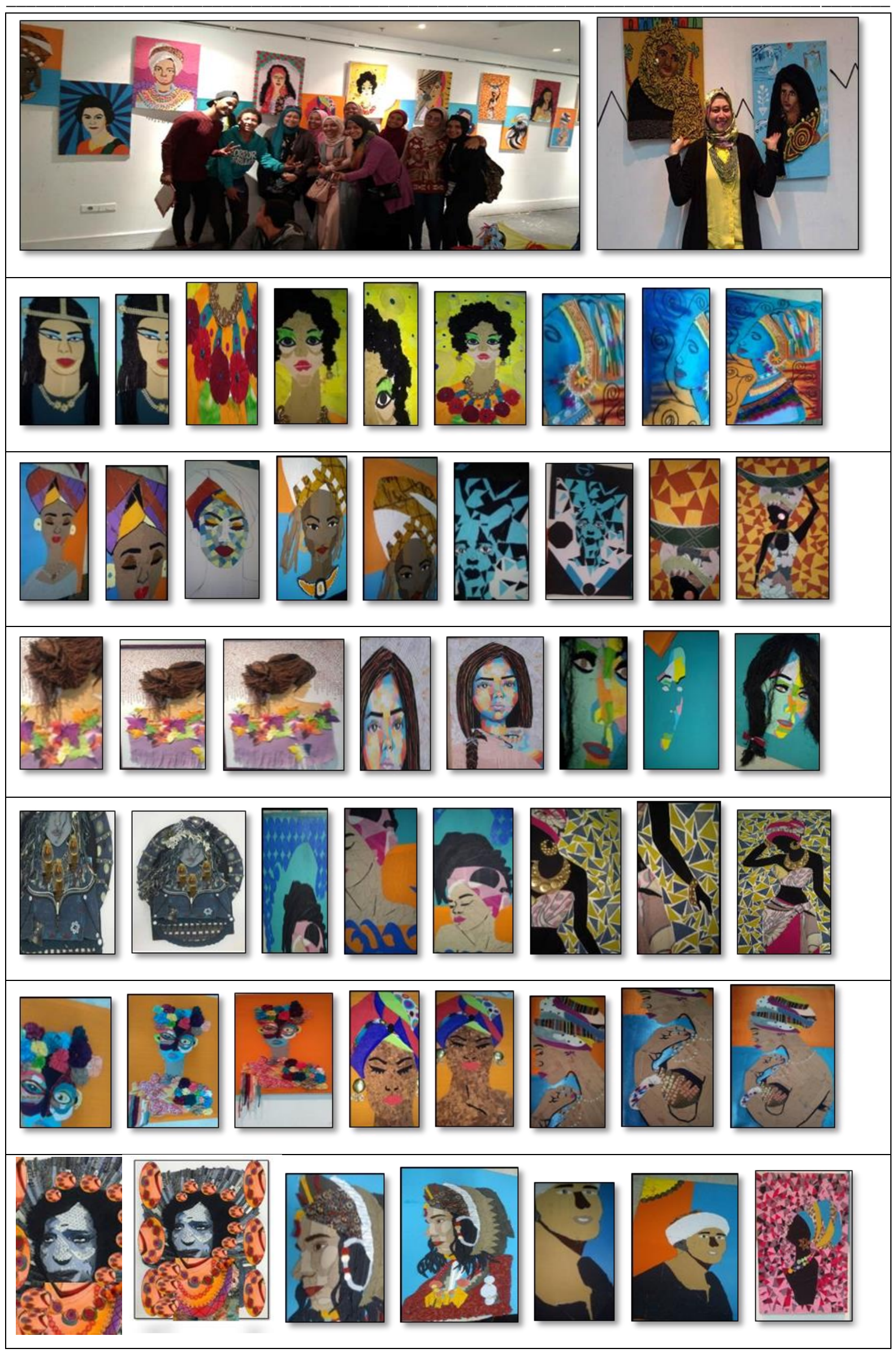




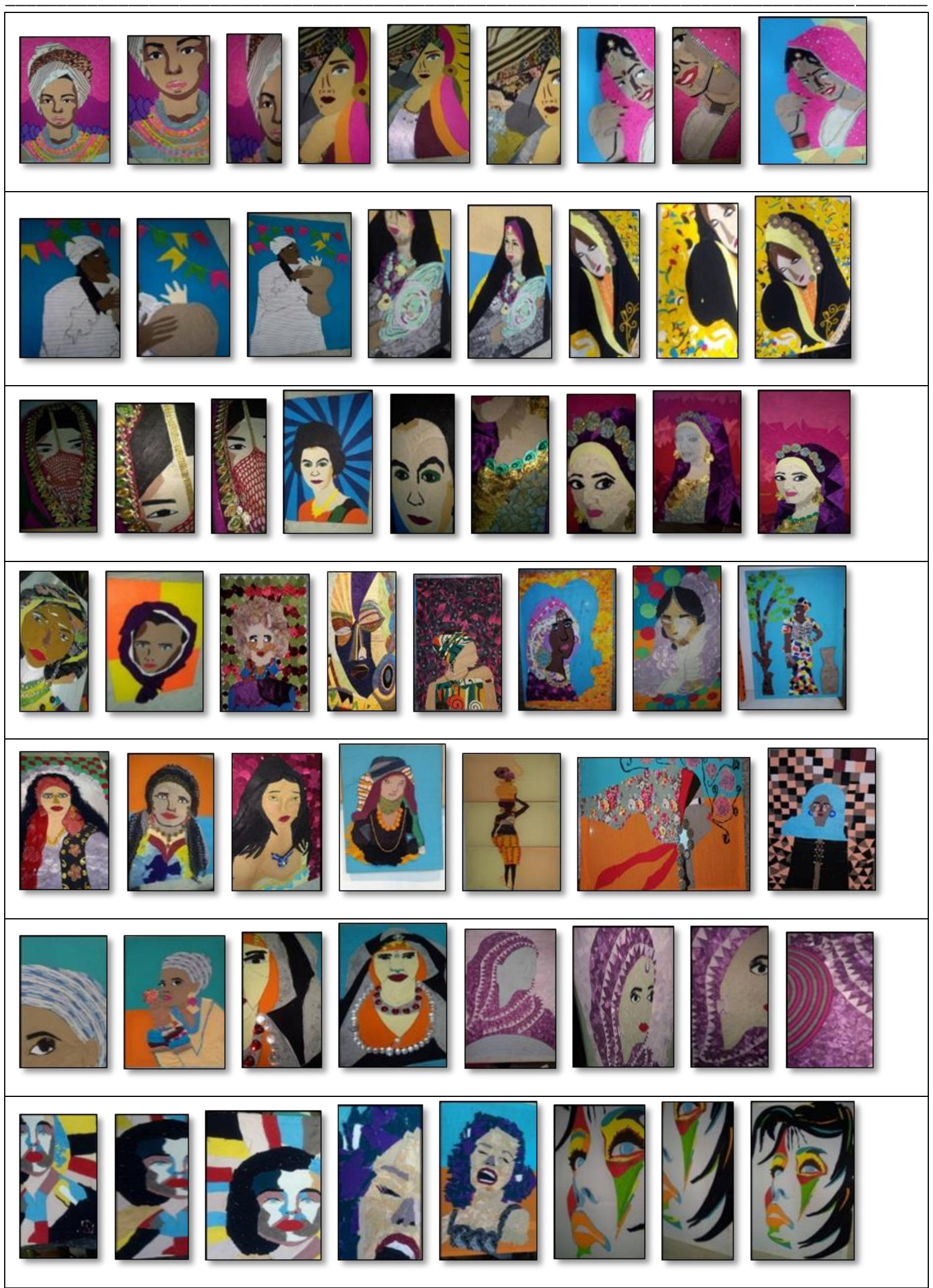

After completing the implementation of the artifacts, an evaluation form was designed for "arbitrators in the field of specialization" (11) arbitrators (Table No. 4, a list of the names of the arbitrators) (Annex No. 1, the product evaluation form that was presented to the arbitrators), 
which included a set of axes to judge the products executed from in terms of design, embroidery, the extent to which aesthetic values are achieved in the products and the extent to which models are suitable for women, and these axes are as follows:

The First Axis: The extent of achieving the design elements in the handicraft.

The Second Axis: The level of formal and plastic principles in the LUNAPIC program.

The Third Axis: The aesthetic and utilitarian values for employing the resulting handicraft.

- After completing the evaluation of the (card), the necessary adjustments were made according to the opinions of the arbitrators.

- Statistical coefficients were performed.

\section{Search Results and Discussion}

To verify the presence of statistically significant differences between the implemented handicrafts and achieving the design elements from the point of view of specialists, the researcher prepared an evaluation form to judge the extent to which the design elements were achieved in the executed works, and after applying it to a sample of (11) academic specialists in the field of (Handicrafts) - the statistical software package SPSS v19 was used to apply the statistical treatments.

Table (4) shows the arithmetic average and variance of the percentage of arbitrators' agreement on the executed works and the extent to which the design elements were achieved

\begin{tabular}{|l|l|l|l|}
\hline $\mathbf{N}$ & Elements of the First Axis (Design Elements) & Average & variance \\
\hline 1 & $\begin{array}{l}\text { Fitting the shape and lines of the design together as an } \\
\text { artistry. }\end{array}$ & 2.86 & 0.14 \\
\hline 2 & Fitting the shape and size of the chosen (figure) shape. & 2.87 & 0.13 \\
\hline 3 & \begin{tabular}{l} 
Color compatibility of the product applied with fabrics. \\
\hline 4
\end{tabular} & $\begin{array}{l}\text { The level of innovation in implementing collage design. } \\
\text { Egyptian taste. }\end{array}$ & 2.85 \\
\hline 5 & $\begin{array}{l}\text { The suitability of the design for its function as hanging or } \\
\text { forming plate. }\end{array}$ & 2.81 & 0.12 \\
\hline 6 & $\begin{array}{l}\text { The extent of achieving originality and modernity in the } \\
\text { design of the chosen work. }\end{array}$ & 2.89 & 0.11 \\
\hline 7
\end{tabular}




\begin{tabular}{|c|c|c|c|}
\hline $\mathbf{N}$ & $\begin{array}{l}\text { Elements of the Second Axis (The Level of Aesthetic Performance of } \\
\text { the Collage with Fabrics) }\end{array}$ & Average & variance \\
\hline 1 & $\begin{array}{l}\text { The size of the design chosen is proportional to the total area of the } \\
\text { handicraft. }\end{array}$ & 2.81 & 0.19 \\
\hline 2 & $\begin{array}{l}\text { Compatibility of the structural formation to integrate design lines } \\
\text { (geometric-organic). }\end{array}$ & 2.79 & 0.21 \\
\hline 3 & Fabric colors are consistent with the handicraft design motifs. & 2.92 & 0.08 \\
\hline 4 & $\begin{array}{l}\text { Matching beads colors with background color and the design of the } \\
\text { fabrics used. }\end{array}$ & 2.92 & 0.08 \\
\hline 5 & The suitability of beads and shiny lobes used. & 2.88 & 0.12 \\
\hline 6 & The colors and the pieces of the fabrics match with each other. & 2.83 & 0.17 \\
\hline 7 & $\begin{array}{l}\text { The suitability of types of fabrics with cutting spaces in the design of the } \\
\text { handicraft. }\end{array}$ & 2.84 & 0.16 \\
\hline 8 & $\begin{array}{l}\text { The extent of accuracy of pasting and knitting the pieces of fabrics } \\
\text { together. }\end{array}$ & 2.96 & 0.04 \\
\hline 9 & $\begin{array}{l}\text { The stability of the surface appearance of the cloth after applying the } \\
\text { techniques on it. }\end{array}$ & 2.96 & 0.04 \\
\hline 10 & $\begin{array}{l}\text { The extent to which aesthetic and functional purpose is achieved for the } \\
\text { handicraft. }\end{array}$ & 2.87 & 0.13 \\
\hline
\end{tabular}

\section{Results}

1. Students' success in studying collage art and implementing formal and plastic principle to employ fabric scraps in forming human terms from folk and heritage arts, then using the LUNAPIC program.

2. It is possible to employ a local environmental material for the practices of the third year students in the course of Handicraft (2) as a formative principle for the handicraft. The pre-engineering design of the remnants of the fabrics can be used to create terms and designs suitable for the implementation of innovative handicrafts.

3. Achieving the objectives of the course to create formal and formative principles for one of the heritage elements (African art, folk art ...) for handicrafts.

4. There is a statistically significant relationship between the degree of acceptance and success of the executed works and the extent of achieving the design elements. 
5. There is a statistically significant relationship between the degree of acceptance and success of the executed artifacts and the extent of achieving the level of aesthetic performance of fabrication with fabric scraps.

6. There is a statistically significant relationship between the degree of acceptance and success of the executed works and the extent to which they achieve aesthetic values

7. There is a statistically significant relationship between the degree of acceptance and success of the executed works and the extent to which they achieve aesthetic values

8. A student exhibition was held at the Palace of Culture, and the handicrafts of the residential units in the Aswan University's common room house were given to the faculty members after the exhibition as an aesthetic touch from them and a continuous and sustainable imprint for them with an aesthetic beneficial thought for their university and their environment.

\section{References}

1. Buthaina Abd Al-Gawad Ahmad (1971): "Of the Heritage, Oya Tissue" Cairo, AlAhram Commercial Printing Press.

2. Joseph Muller (1988): “Art in the Twentieth Century, translated by Maha Farah AlKhoury, Damascus, Dar Tlass, Syria.

3. Zakaria Ibrahim (1976): "The Problem of Art”, Part (3), Egypt Library, Cairo.

4. Unknown (1979): "Is art an Industry?" Article 36 of December Magazine.

5. Abdel Hamid Younes (1979): “The Popular Heritage”, (Your Book) series (19), Cairo, Egyptian House of Knowledge.

6. Abd Al-Muttalib Amin Al-Quraiti (1995): An Introduction to the Psychology of Children's Drawings, Dar Al Maaref, Cairo.

7. Ali Ahmad, Ahmad Muhammad (2004). Evaluation in the Educational System, Riyadh, Al-Rushed Library.

8. Saad El-Khadem (1959): "History of Folk Fashion in Egypt" Cairo, Dar Al Maaref.

9. Sionide Merry, Robert Stone (1994): "Handicrafts and Contemporary Culture," translated by Muhammad Khalifa Barakat, Cairo, Arab Record Foundation, p. 43.

10. Muhammad Hussein Judeh (1999): "The New in Art and Art Education" Dar AlMasirah for Publishing, Distribution and Printing - Amman, 2nd Edition.

11. Mahmoud Al-Basyouni (1965): “Artistic Culture and Education," Dar Al Maaref, Cairo.

12. Monther Sameh Al-Ghanoum (1427 AH): "An Introduction to Taste and Art Criticism” Dar Al-Sumaiyi for Publishing, 1st Edition, Riyadh, Kingdom of Saudi 
Arabia.

13. Amy Demp(2002):" An Encyclopedic guide to Modern Art Styles Schools and Movements, Thames \& Hudson, London,p32

14. Janez Strehovec (2016). Text as Ride. Electronic Literature and New Media Art. Morgantown: West Virginia University Press (Computing Literature book series)

15. Lopes, Dominic McIver. (2009). A Philosophy of Computer Art. London: Routledge.

16. United Nations Educational, Scientific and Cultural Organization (2006): Road Map for Art Education, “The World Conference on Arts Education: Building Creative Capacities for the 21st Century Lisbon" 6-9.

17. Valentino Catricalà, Media Art. Towards a New Definition of Arts in the Age of Technology. Siena: Gli Ori, 2015.

18. Ahmed Muhammad Al-Baghdadi (2011): "Utilizing Wood Waste to create Plastic Formulas in Painting: an Experimental Study. Journal of Specific Education Research, Mansoura University, Egypt.

19. Arts Gulf Newspaper, Thursday, 12, Jumada-Al-Thani 1441 AH, 6 February 2020 Renewal and Postmodernity in Arab Plastic Arts Experiences.

20. Ashraf Mohamed Abdel Qader (1989): "Benefiting from the Costume and Adornment Works of Bedouins in the New Valley as an Entry Point to enrich the Subject of Handicrafts." MA, Faculty of Art Education, Helwan University.

21. Al-Noihi Abdul-Bari (2004): "The Economic Feasibility of Recycling Municipal Solid Waste - A Case Study on the City of Jeddah" MA, King Abdul-Aziz University.

22. Rehab Muhammad Abu Zaid, 2001: "Creating Wall Hangings with Plastics and Fabrics”, an unpublished Master Thesis, Faculty of Art Education, Helwan University.

23. Zahraa Abdullah (2008): "Pop as an Introduction to Creating Collective Art in Painting” MA, College of Education, King Saud University, Kingdom of Saudi Arabia.

24. Zainab Ahmed Abdel Aziz (2011): “A proposed Project to utilize the Waste of Fabrics for Ready-to-Wear Factories." Specific Education Research Journal, Mansoura University, Issue (21), April.

25. Sally Imad Farouk Abu Hamila (2016): "Benefiting from Combined Materials in creating Handicrafts inspired by Abstract Nature - Master Thesis - Art Education - Ain Shams University.

26. Suleiman Mahmoud 1982: "The Role of Environmental Materials in Artistic Formation" Journal of Research and Studies of Helwan University, No. 3

27. Suzan Gerges (2013): “An updated Plastic Vision of the Aesthetics of the Ornamental 
Complexity of Tapes in the Field of Handicrafts in the Light of the Art of Kumihimo" MA, Faculty of Art Education, Helwan University.

28. Ghada Mustafa Rashwan (2014): “The Structural Foundations and Formal Variables of Paper Models as a Suggested Entry for the Development of Thinking in the Autistic Child, Journal of Research in the Sciences and Specific Arts - Alexandria University Conference on Specific Education for Sustainable Development 12: 13 November.

29. Fatima Abdel-Aziz Al-Mahmoudi 1988: "Synthesis of Some Environmental Materials Used in Selections of Popular Handicrafts to make Innovative Accessories for Decoration" Ph.D., Faculty of Art Education, Helwan University.

30. Muhammad Salah Al-Tohamy (2006): Philosophical and Aesthetic Approaches to Employing Ready-Made Things in Sculpture for the Second Half in the Twentieth Century, Ph.D., Faculty of Art Education, Helwan University.

31. Huda Hammad Zaki Al-Sayed (1979): The Experimental Method in Modern Painting and its Innovative and Educational Methods, unpublished PhD Thesis, Faculty of Art Education, Helwan University.

32. Hadeel Hassan Ibrahim (1991): "The Art of Fabrication as an Introduction to Building a Program for Handicrafts for Students of the Faculty of Art Education" Ph.D. Thesis, Faculty of Art Education, Helwan University.

33. Wagdy Rifaat Farid, (2012): “The Plastic Capabilities of Consumed Raw Materials to produce Innovative Handicrafts Based on Experimentation. A working paper presented to the Third International Conference (South-South Dialogue) entitled Plastic Arts and Global Changes, Assiut University.

34. Yasser Muhammad Fadl (2012): "The Culture of processing Environmental Materials in the Art of Painting as an Introduction to developing Environmental Awareness and Aesthetic Sense" for students of the Faculty of Specific Education in Asyut, a working paper submitted to the 9th International Conference - Conference of Art and Culture of the Others, Faculty of Fine Arts, Minya University, 3 / 2012, Egypt.

35. https://artsgulf.com/articles/672500.html

36. Wael Mohamed Kamel El-Sayed AFIFI and Basma Mohamed YOUSSEF, ANCIENT EGYPTIAN FURNITURE IN THE LIGHT OF THE CHARACTERISTICS THAT LED TO ITS PRESERVATION TILL NOW, International Journal of Multidisciplinary Studies in Art and Technology, Vol. 1, No. 1, 2018, pp. 14-19.

37. https://www6.lunapic.com/editor/?action=neon\&fbclid=IwAR08xK_wesbMyfj1IcMv $\mathrm{cPvg}$ 
38. http://sayidati.banoata.not

39. https://www.scientificamerican.com/arabic/articles/news/science-of-embalming-ishistorically-precedes-what-we-think/

Annex No. (1) Product Evaluation Form for "Arbitrators in the Field of Specialization"

\begin{tabular}{|c|c|c|c|c|}
\hline $\mathrm{N}$ & phrase & Appropriate & $\begin{array}{l}\text { Somewhat } \\
\text { Appropriate }\end{array}$ & Inappropriate \\
\hline & $\begin{array}{l}\text { The First Axis: The Extent to which the Design Elements } \\
\text { are achieved and the Quality of the Design }\end{array}$ & & & \\
\hline 1 & The suitability of the shape and design lines together. & & & \\
\hline 2 & $\begin{array}{l}\text { The suitability of the shape and size of the decorative unit to } \\
\text { the model. }\end{array}$ & & & \\
\hline 3 & Color compatibility of the implemented product. & & & \\
\hline 4 & The level of innovation and innovation in design. & & & \\
\hline 5 & $\begin{array}{l}\text { The extent to which the executed design fits the Egyptian } \\
\text { taste. }\end{array}$ & & & \\
\hline 6 & The suitability of the design for its intended purpose. & & & \\
\hline \multirow[t]{2}{*}{7} & The extent of achieving originality and contemporary design. & & & \\
\hline & $\begin{array}{l}\text { The Second Axis: The Level of Aesthetic Performance and } \\
\text { the Quality of the Embroidery }\end{array}$ & & & \\
\hline 8 & $\begin{array}{l}\text { The suitability of the size of the decorative unit with the total } \\
\text { spaces of the design. }\end{array}$ & & & \\
\hline 9 & $\begin{array}{l}\text { The structural formation of the decorative unit corresponds to } \\
\text { the design lines. }\end{array}$ & & & \\
\hline 10 & The color consistency of the decorative unit. & & & \\
\hline 11 & $\begin{array}{l}\text { Matching the colors of the beads with the color of the clothes } \\
\text { used. }\end{array}$ & & & \\
\hline 12 & $\begin{array}{l}\text { The suitability of shiny beads and lobes used for embroidery } \\
\text { stitches. }\end{array}$ & & & \\
\hline 13 & The embroidery stitches fit together. & & & \\
\hline 14 & The used stitches fit the model. & & & \\
\hline
\end{tabular}




\begin{tabular}{|l|l|l|l|l|}
\hline 15 & How accurately the stitch is executed. & & & \\
\hline 16 & The degree of regularity of the stitch. & & & \\
\hline 17 & $\begin{array}{l}\text { The stability of the surface appearance of the fabric after } \\
\text { applying the embroidery. }\end{array}$ & & & \\
\hline 18 & The extent to which the aesthetic and functional purpose of \\
the model is achieved. & The Third Axis: Aesthetic Values & & & \\
\hline 19 & Balance in design. & & & \\
\hline 20 & Rhythm and movement in the design of the model. & & & \\
\hline 21 & Unity and interconnectedness among design elements. & & & \\
\hline 22 & $\begin{array}{l}\text { Compatibility of the materials used with the implemented } \\
\text { product. }\end{array}$ & & & \\
\hline
\end{tabular}

Received: September 5, 2018

Accepted: November 7, 2018 